\title{
Altitude variations of cosmic ray induced production of aerosols: Implications for global cloudiness and climate
}

\author{
Fangqun $\mathrm{Yu}$ \\ Atmospheric Sciences Research Center, State University of New York, Albany, New York, USA \\ Received 31 July 2001; revised 29 November 2001; accepted 7 December 2001; published 19 July 2002.
}

[1] The indirect radiative forcing of atmospheric aerosols is sensitive to particle size and concentration, which are influenced significantly by nucleation processes. Via its role in aerosol formation, cosmic ray may affect the cloud condensation nuclei abundance and hence the global cloud properties and climate. Systematic variations in ionization rates due to the modulation of cosmic ray radiation by the solar cycle are sufficient to cause notable variations in aerosol production, and we find that the signs of such variations are altitudedependent. Our study indicates that an increase in cosmic ray fluxes generally leads to an increase in particle production in the lower troposphere but a decrease in particle production in the upper troposphere. The main reason of such an altitude-dependent influence is that the dependence of particle production rate on ionization rate is a complex function of ionization rate itself, as well as precursor gas concentration and ambient conditions. The implications of altitude variations of cosmic ray-induced aerosol production on global cloudiness and climate are discussed. In addition to the reported positive correlation between cosmic ray variations and low cloudiness, our analysis reveals that high cloudiness may be anti-correlated with cosmic ray variations if volcano and El Niño impacts are excluded. The observed different correlations between cosmic ray variations and low, middle and high cloud anomalies appear to be consistent with the predicted different sensitivities of particle production to cosmic ray changes at different altitudes. A systematic change in global cloudiness may change the atmosphere heating profile, and if confirmed, may provide the external forcing needed to reconcile the different surface and troposphere temperature trends. Much more work is needed to understand how and how much the cosmic ray variations will affect the global cloud properties and climate. INDEX TERMS: 0305 Atmospheric Composition and Structure: Aerosols and particles (0345, 4801); 0320 Atmospheric Composition and Structure: Cloud physics and chemistry; 1650 Global Change: Solar variability; 7823 Space Plasma Physics: Ionization processes; KEYWORDS: cosmic ray, nucleation, altitude dependent, condensation nuclei, cloudiness, climate change

\section{Introduction}

[2] There seems little doubt that links exist between solar variability and terrestrial climate on century, decade, and shorter timescales [Reid, 2000]. For example, historical data strongly suggest that the Little Ice Age (from 1550 to 1850 A.D., when the mean temperature was colder by $\sim 1^{\circ} \mathrm{C}$ ) was most likely caused by variability of the sun [Eddy, 1976]. The measured $0.1 \%$ level of the long-term total irradiance variations (i.e., solar direct effect on climate change) is generally considered to be too small $\left(0.3 \mathrm{~W} / \mathrm{m}^{2}\right.$, globally averaged) to account for the observed changes in the Earth's climate. Detailed fits of global and hemispherical temperatures since the mid 19th century with empirical models involving the enhanced greenhouse effect and solar variability require an amplification of irradiance effect by factor $>2.5$ to quantitatively explain the observed global temperature change [e.g., Kelly and

Copyright 2002 by the American Geophysical Union. 0148-0227/02/2001JA000248\$09.00
Wigley, 1992; Soon et al., 1996; Lockwood, 2001]. The following mechanisms for the amplification of the solar variability have been proposed: (1) via ultraviolet (UV) induced changes in stratospheric ozone and heating rate (i.e., UV ozone hypothesis) [e.g., Haigh, 1996, 1999; Shindell et al., 1999], (2) via ionosphere-Earth current density-induced changes in cloud microphysics (i.e., current density-cloud hypothesis) [e.g., Tinsley and Dean, 1991; Tinsley, 2000], and (3) via galactic cosmic ray (GCR) induced changes in condensation nuclei (CN) formation and cloudiness (i.e., GCR-CN-cloud hypothesis) [e.g., Dickinson, 1975].

[3] During a solar cycle, changes in the UV radiation of the solar spectrum are of the order of $10 \%$. On the basis of the UV ozone hypothesis the UV-induced changes in stratospheric ozone and heating rate alter the stratospheric circulation and the Hadley circulation, which then affect the equator-to-pole energy transport and the lower atmosphere temperature [e.g., Haigh, 1996, 1999; Shindell et al., 1999]. The UV ozone hypothesis appears to reproduces many observed 11-year oscillations (including the relative 
long record of geopotential height variations) [e.g., Shindell et al., 1999].

[4] The solar wind affects the galactic cosmic ray flux, the precipitation of relativistic electrons, and the ionospheric potential distribution in the polar cap, and each of these modulates the ionosphere-earth current density. On the basis of the current density-cloud hypothesis the variations in the current density change the charge status of aerosols that affect the ice production rate and hence the cloud microphysics and climate [e.g., Tinsley and Dean, 1991; Tinsley, 2000]. The underlying mechanism is that charged aerosols are more effective than neutral aerosols as ice nuclei (i.e., electrofreezing) and that the enhanced collections of charged evaporation nuclei by supercooled droplets enhance the production of ice by contact ice nucleation (i.e., electroscavenging). Both electrofreezing and electroscavenging involve an increase in ice production with increasing current density [e.g, Tinsley and Dean, 1991; Tinsley, 2000]. The current density-cloud hypothesis appears to explain solar cycle effects on winter storm dynamics as well as the dayto-day changes of Wilcox and Roberts Effects [e.g., Tinsley, 2000]. Kniveton and Todd [2001] found evidence of a statistically strong relationship between cosmic ray flux, precipitation and precipitation efficiency over ocean surfaces at midlatitudes to high latitudes, and they pointed out that their results are broadly consistent with the current density-cloud hypothesis.

[5] Recently, the GCR-CN-cloud hypothesis [e.g., Dickinson, 1975] has received increasing attention, as a result of a report indicating that global cloud cover correlates closely with the GCR intensity [Svensmark and Friis-Christensen, 1997] and a new nucleation theory showing that GCR ionization may play an important role in the production of new particles under typical tropospheric conditions $[Y u$ and Turco, 2000, 2001].

[6] Svensmark and Friis-Christensen [1997, hereinafter referred to as SFC] first reported that total cloud cover over midlatitude ocean correlates closely with the GCR intensity. The cloud data analyzed include the $\mathrm{C} 2$ data sets from the International Satellite Cloud Climatology Project (ISCCP). Because of its potential importance and implication, SFC's GCR-cloud-climate hypothesis has been under close scrutiny [e.g., Kernthaler et al., 1999; Jørgensen and Hansen, 2000; Kristjánsson and Kristiansen, 2000; Wagner et al., 2001]. Most of the critique against the old data on which SFC's conclusion are based, such as data calibration problem, selectiveness of geographical region, and cloud types, has largely been addressed in the new analyses of the International Satellite Cloud Climate Project (ISCCP) D2 data set [Marsh and Svensmark, 2000a, 2000b]. The new ISCCP-D2 data, which come from an improvement of procedures leading to the $\mathrm{C} 2$ data, are global and cover the period from July 1983 to September 1994 [Rossow and Schiffer, 1999]. Following the SFC's discussions, questions were also raised with regard to the influence of volcanoes and El Niño Southern Oscillation (ENSO) events on cloud cover during the measurement period. While volcanoes and ENSO events may affect the cloud cover during the event years, it seems unlikely that they could explain the major features of the cloud variability [Kirkby and Laaksonen, 2000].

[7] Analyses of the ISCCP-D2 data indicate the presence of a significant positive correlation between GCR intensity and the frequency of low clouds, below $\sim 3.2 \mathrm{~km}$, but none with clouds at higher altitudes [Marsh and Svensmark, 2000a, 2000b; Palle and Butler, 2000]. In addition to ISCCP, Defense Meteorological Satellite Program (DMSP) also produces frequency of cloud occurrence over ocean [Weng and Grody, 1994]. DMSP only detects liquid water clouds, which are mostly made up of low clouds. Kristjánsson and Kristiansen [2000] showed that the low cloudiness from DMSP is also highly correlated with GCR radiation, and the correlation coefficient is 0.75 globally and 0.864 over the midlatitude oceans. The reported significant correlation of GCR variations with the frequency of low clouds, but none with middle and high clouds, is surprising since the solar modulation of the cosmic ray intensity is a maximum around tropopause and decreases with decreasing altitudes. In order to establish a causal link between GCR variations and global cloud properties, a convincing physical mechanism must be understood and such mechanism should be able to explain why the correlation between solar activity and cloud cover exists only with low-level clouds, and not with higher clouds where the strongest impact should be expected.

[8] All of the three hypotheses discussed above (i.e., UV ozone hypothesis, current density-cloud hypothesis, and GCR-CN-cloud hypothesis) have the potentials to affect the properties of clouds. However, Marsh and Svensmark [2000a, 2000b] pointed out that observations of atmospheric parameters (vertical profiles of water vapor and temperature) from the TIROS Observed Vertical Sounder (TOVS) do not support a solar cloud link through tropospheric dynamics influenced by UV absorption in the stratosphere. The low clouds are warm and comprise of liquid water droplets (note that the mean cloud top temperature of ISCCP low clouds is $\sim 281 \mathrm{~K}$ [Rossow and Schiffer, 1999] and DMSP only detects liquid water clouds). Recently, Tinsley et al. [2001] suggested that electroscavenging might also work in warm liquid clouds by reducing the concentration of the small evaporation nuclei and thus $\mathrm{CCN}$ for next cycle of cloud formation. Since the variation of current density at low latitudes is anticorrelated with the cosmic ray variation over the solar cycle [e.g., Tinsley, 1996], the warm cloud electroscavenging may actually contribute to the reported positive correlation between GCR variations and low cloud cover (but only at low latitudes). However, the absence of similar correlations between GCR variations and middle/high cloud cover [Marsh and Svensmark, 2000a, 2000b] remains to be explained.

[9] The objective of this paper is to explore if the GCRCN-cloud hypothesis can explain the observed altitudedependent correlations between GCR and global cloudiness, focusing on the altitude variations of GCR-induced aerosol production. The climate implications are also discussed.

\section{GCR-CN-CCN-Cloud Hypothesis}

[10] Figure 1 shows three key processes involved in the GCR-CN-CCN-cloud hypothesis.

[11] The first key process is that the modulation of galactic cosmic radiation by the solar cycle will cause a notable variation in aerosol production and $\mathrm{CN}$ population in the lower atmosphere. Yu and Turco [2001] demonstrated 


\section{GCR-CN-CCN-Cloud Hypothesis}

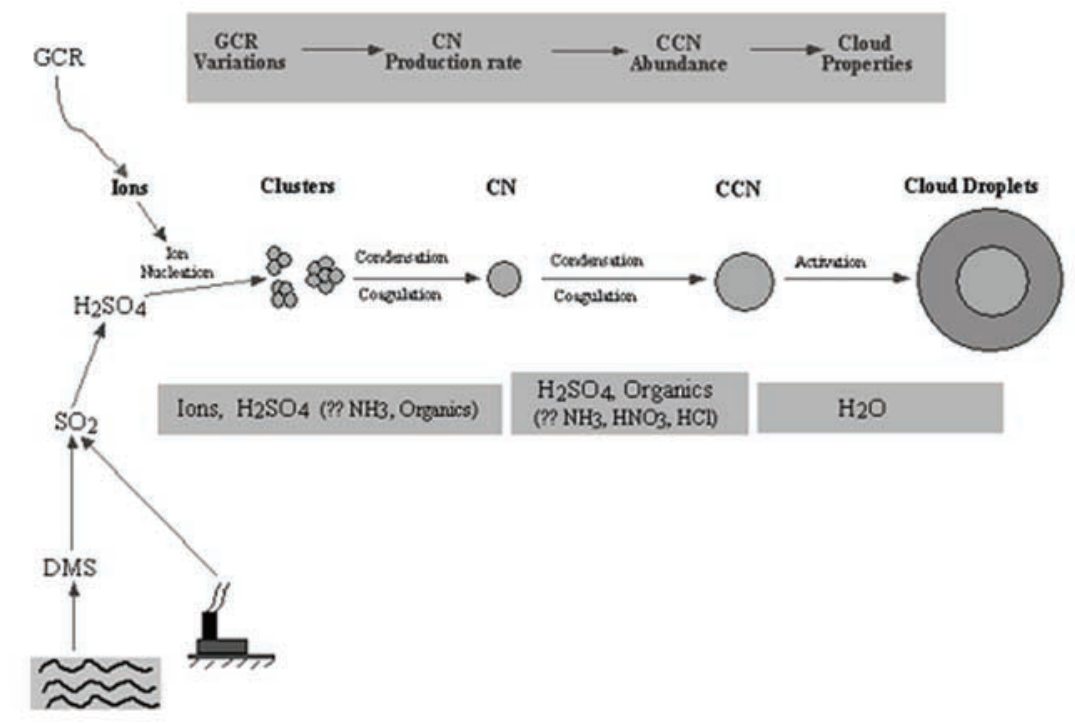

Figure 1. Schematic illustrating of GCR-CN-CCN-cloud hypothesis that, if confirmed, might explain the correlation between variations of GCR flux and low cloud cover. The possible dominating species involved in the different phases of $\mathrm{CN}$ formation and growth processes are also indicated. The organics species may play an important role in growing the $\mathrm{CN}$ into the size of $\mathrm{CCN}$.

that systematic variations in ionization levels due to the modulation of galactic cosmic radiation by the solar cycle are sufficient to cause a notable variation in $\mathrm{CN}$ production in the marine boundary layer. As we will show below, the effects of ionization variations on $\mathrm{CN}$ production rate depend on ionization rate, concentrations of precursor gases, and ambient conditions.

[12] The second key process is that a systematic change in the ultrafine particle production rate will affect the population of cloud condensation nuclei (CCN). In order to affect cloud properties the newly formed ultrafine particles have to grow to the size of typical CCN. In order to be activated as $\mathrm{CCN}$ for clouds reasonably common in the lower atmosphere, typical atmospheric particles should have a minimum dry diameter of $\sim 30-50 \mathrm{~nm}$ (corresponding to wet diameter at $\mathrm{RH}=90 \%$ of $\sim 50-80 \mathrm{~nm}$ ) [e.g., Hegg, 1990; Novakov and Penner, 1993; Kaufman and Tanre, 1994; Hudson and Da, 1996; Shaw et al., 1998]. There exist observations that indicate that ultrafine particles can grow by condensation to a dry diameter of $\sim 30-50 \mathrm{~nm}$ within 1 day [e.g., Kulmala et al., 1998; Birmili and Wiedensohler, 2000]. Certain organic species may contribute significantly to grow the newly formed particles to the size of CCN [e.g., Novakov and Penner, 1993]. Since the dominating number of cloud condensation nuclei (CCN) is evolved from newly formed ultrafine particles [e.g., Hegg, 1990; Kaufman and Tanre, 1994], it is physically plausible that a systematic variation in ultrafine production rate will affect the $\mathrm{CCN}$ abundance, though the magnitude of such effect is currently unknown.

[13] The third process is that a change in $\mathrm{CCN}$ abundance will affect the cloud properties. It is well known that the CCN abundance affects cloud properties [Twomey, 1977, 1991; Albrecht, 1989; Hobbs, 1993]. Clouds that form in air containing high $\mathrm{CCN}$ concentrations tend to have high droplet concentrations, which lead to an increase in both albedo and absorption. Increases in the $\mathrm{CCN}$ concentration also inhibit rainfall and therefore increase cloud lifetimes (cloud coverage). These effects, which are due to more, smaller droplets at fixed liquid water content, are particularly significant in marine air, where the CCN concentrations are generally quite low.

[14] In order to assess the magnitude of the effect of GCR variations on global cloudiness, all three processes discussed above have to be quantitatively understood. This is not an easy job and requires many further investigations. However, as far as the sign of the effect (e.g., the correlation between GCR variations and cloudiness) is concerned, the first process is critical. An increase in $\mathrm{CN}$ production is expected to increase the $\mathrm{CCN}$ abundance and cloud cover, but an increase in GCR fluxes does not always lead to an increase in $\mathrm{CN}$ production. In section 3 we discuss the influence of GCR-induced ionization changes on particle production rate under different conditions, focusing on the potential altitude-dependent influence of GCR variations on particle production and $\mathrm{CN}$ abundance.

\section{Altitude-Dependent Influence of GCR Ionization on Particle Formation}

[15] Ambient ions are continuously generated by galactic cosmic rays at the rate of $\sim 2$ ion pairs $\mathrm{cm}^{-3} \mathrm{~s}^{-1}$ at ground level and up to $\sim 20-30$ ion pairs $\mathrm{cm}^{-3} \mathrm{~s}^{-1}$ in the upper troposphere [Millikan et al., 1944; Neher, 1971]. Because of enhanced growth and stability of charged clusters (as a consequence of electrostatic interactions), air ions produced from GCR ionization may play an important role in the production of new particles under 
typical tropospheric conditions [Yu and Turco, 2000, 2001]. The proposed ion-mediated nucleation (IMN) theory can physically explain the enhanced growth rate (a factor of $\sim 10$ ) of subnanometer clusters and the square of sulfuric vapor concentration $\left(\left[\mathrm{H}_{2} \mathrm{SO}_{4}\right]^{2}\right)$ dependence of nucleation rate as observed by Weber et al. [1997] and seems to account consistently for ultrafine aerosol formation in jet plumes [Yu and Turco, 1997; Yu et al., 1998, 1999; Kärcher et al., 1998], in motor vehicle wake [Yu, 2001], in marine boundary layer [Yu and Turco, 2001], in clean continental air [Yu and Turco, 2000], as well as for the diurnal variation in the atmospheric mobility spectrum [Yu and Turco, 2000].

[16] It is generally known that sulfuric acid vapor concentration $\left(\left[\mathrm{H}_{2} \mathrm{SO}_{4}\right]\right)$, temperature $(T)$, relative humidity $(\mathrm{RH})$, pressure $(P)$, and the surface area of preexisting particles are among the list of parameters controlling the particle formation in the troposphere. The IMN theory adds another important parameter-ion concentration ([ion], or ionization rate $Q$ ) to this list. Here we study the influence of GCR ionization variations on particle formation and $\mathrm{CN}$ abundance at different altitudes. We employ an advanced particle microphysics (APM) model that simulates a sizeresolved multicomponent aerosol system via a unified collisional mechanism involving both neutral and charged particles down to molecular sizes [Yu and Turco, 2001]. The size-resolved ion-ion recombination coefficients, ionneutral collision kernels, and neutral-neutral interaction coefficients calculated in the model are physically consistent and naturally altitude (temperature, pressure, and relative humidity) dependent [Yu and Turco, 2001]. For the simulations presented below, the ion concentration is initialized as $\sqrt{Q / \alpha}$, where $\alpha$ is ion-ion recombination coefficient. The preexisting particles are initialized as two lognormal modes with total number densities of 19.5 $\mathrm{cm}^{-3}$ and $0.6 \mathrm{~cm}^{-3}$, median dry diameters of 0.09 and $0.3 \mu \mathrm{m}$, and standard deviations of 1.6 and 1.5 , respectively. This gives an initial wet surface area of $\sim 4.2 \mu \mathrm{m}^{2} / \mathrm{cm}^{3}$ at $90 \%$ relative humidity, corresponding to a cloud-processed clean air mass where typical significant aerosol nucleation has been observed.

[17] Figure 2 shows the total condensation nuclei bigger than $3 \mathrm{~nm}\left(N_{d}>3 \mathrm{~nm}\right)$ after three hours of simulations as a function of ionization rates at three different altitudes $(0,5$, $8 \mathrm{~km})$. The values of $\left[\mathrm{H}_{2} \mathrm{SO}_{4}\right], T, P$, and $\mathrm{RH}$ for each altitude (as specified in the Figure 2 legend) are fixed during the 3-hour simulations. $Q$ is fixed during each 3hour simulation and the values of representative $Q$ s for each altitude roughly correspond to the positions of the labels on each curve. It is clear from Figure 2 that significant number of ultrafine particles have formed under all the considered conditions. Most of these newly formed particles began as electrically charged clusters that have the advantage of enhanced growth and stability due to electrostatic effects. The neutral subcritical clusters, on the other hand, grow too slowly to exceed the critical size under the prevailing conditions. The production rate of ultrafine particles is most sensitive to $\left[\mathrm{H}_{2} \mathrm{SO}_{4}\right]$ and [ion] (or ionization rate). $\left[\mathrm{H}_{2} \mathrm{SO}_{4}\right]$ controls the growth rate of ion clusters, while [ion] determines the lifetime of charged clusters and the availability of ions. The neutralization by ion-ion recombination will make the growing charged

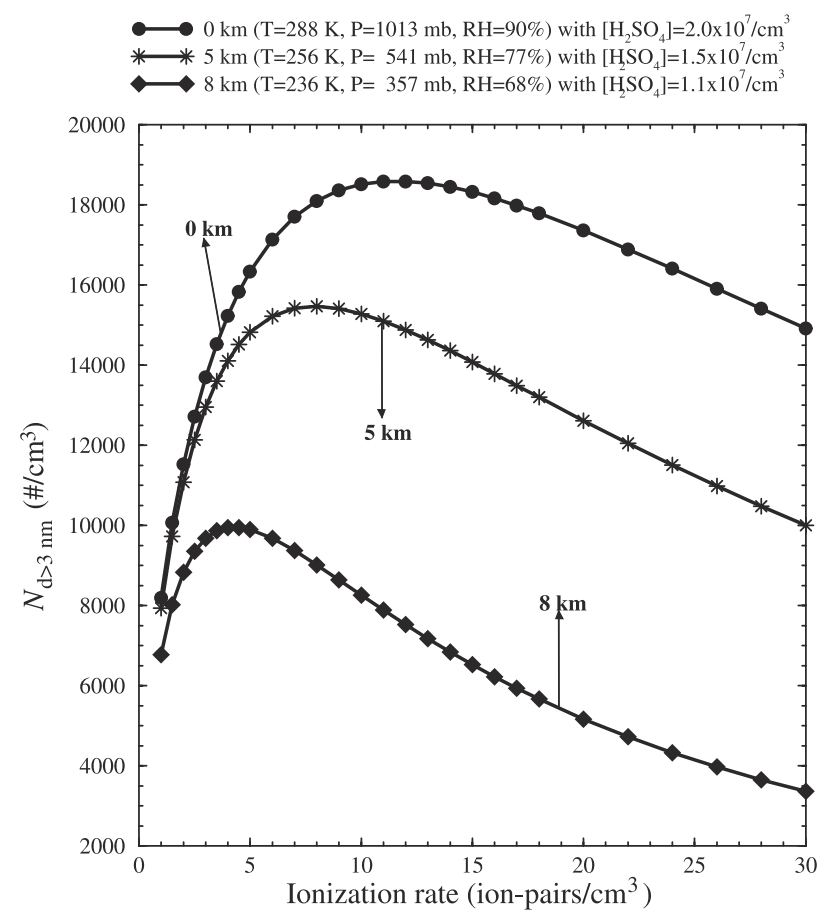

Figure 2. Simulated concentrations of total condensation nuclei larger than $3 \mathrm{~nm}\left(N_{\mathrm{d}}>3 \mathrm{~nm}\right)$ after three hour of simulations for various ionization rates $(Q)$ at three altitudes $(0,5$, and $8 \mathrm{~km}) . N_{\mathrm{d}>3 \mathrm{~nm}}$ increases rapidly in the low cloud region but decreases rapidly in the high cloud region as $Q$ increases.

clusters lose their growth advantage and the resulting neutral clusters may dissociate if smaller than the critical size. At typical $\left[\mathrm{H}_{2} \mathrm{SO}_{4}\right]$ where nucleation has been observed, for very low $Q$ most of the ion clusters have sufficient time to reach the larger stable sizes prior to recombination and the nucleation rate is limited by $Q$. As $Q$ increases, ion concentration increases, but the lifetime of ions decreases and hence the fraction of ions having sufficient time to grow to the larger stable sizes decreases. As a result, the total number of particles nucleated first increases but later on decreases as $Q$ increases. Figure 2 demonstrates that, as $Q$ increases, $N_{\mathrm{d}>3 \mathrm{~nm}}$ increases rapidly in the low cloud region but decreases in the high cloud region. The $Q$ value at turning point (i.e., $d N / d Q=$ $0)$ is sensitive to $\left[\mathrm{H}_{2} \mathrm{SO}_{4}\right]$ and is most likely located in middle cloud region.

[18] During a solar cycle the values of $Q$ vary by $\sim 20-$ $25 \%$ in the upper troposphere and $\sim 5-10 \%$ in the lower troposphere for high latitudes, and by $\sim 4-7 \%$ in the upper troposphere and $\sim 3-5 \%$ in the lower troposphere for low latitudes [Ney, 1959]. To study the effect of such systematic change of ionization rates on particle production at different altitudes, we increase the baseline ionization rate at each chosen altitude by $20 \%$ and compare the $\mathrm{CN}$ abundance after three hours of simulations. The altitude-dependent values of $\left[\mathrm{H}_{2} \mathrm{SO}_{4}\right], Q, T, \mathrm{RH}, P$, and the surface area of preexisting particles are specified and some of them are shown in Figure 3. The baseline values of $Q$ at different altitudes are from observations [Millikan et al., 1944; Neher, 

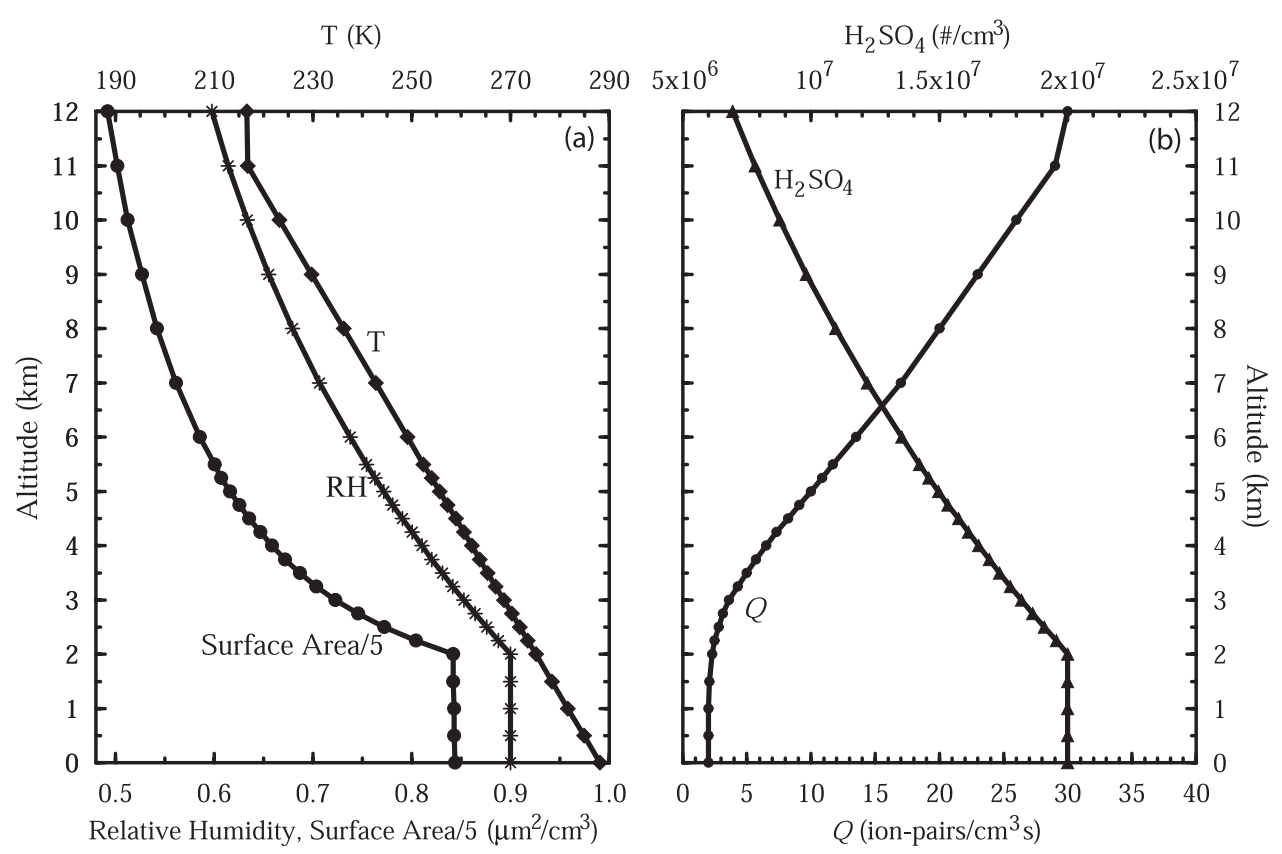

Figure 3. The vertical profiles of (a) temperature $T$, relative humidity (RH), and initial surface area of ambient aerosols, (b) $\left[\mathrm{H}_{2} \mathrm{SO}_{4}\right]$ and baseline $Q$, used in the model to study the effect of a systematic change in ionization rates on particle production at different altitudes.

1971], and the temperature and pressure are according to the U.S. Standard Atmosphere. The $\left[\mathrm{H}_{2} \mathrm{SO}_{4}\right]$ and $\mathrm{RH}$ are parameterized in a way so that they are constant in the lowest 2 $\mathrm{km}$ of atmosphere $\left(2 \times 10^{7} \mathrm{~cm}^{-3}\right.$ and $90 \%$, respectively) and gradually decrease with altitude above $2 \mathrm{~km}$. These parameterizations are reasonable and are within the range of the observed values in various field campaigns [Weber et al., 1999; Clarke et al., 1999].

[19] Figure 4 shows the total condensation nuclei bigger than $3 \mathrm{~nm}\left(N_{d}>3 \mathrm{~nm}\right)$ after 3 hours of simulations at different altitudes. The line with open cycles is for the baseline $Q$ values while the line with filled cycles is for $Q$ values $20 \%$ over the corresponding baseline values. The shaded areas in Figure 4 are low, middle, and high cloud regions as defined in ISCCP cloud data. $\left[\mathrm{H}_{2} \mathrm{SO}_{4}\right]$, $Q, T, \mathrm{RH}$ at each altitude (see Figure 3 ) are fixed during the 3-hour simulations. It is clear from Figure 4 that an increase in GCR ionization rate associated with solar activity leads to an increase in the ultrafine production rate (i.e., $d N / d Q>0$ ) in the lower troposphere (as indicated by the arrows) but a decrease in the ultrafine production rate (i.e., $d N / d Q<0$ ) in the upper troposphere. In the middle troposphere, $d N / d Q$ changes sign and the average value of $d N / d Q$ is small compared to that of lower and upper troposphere. It is interesting to note that the optimum particle formation layer is located in the middle troposphere $(3-5 \mathrm{~km}$ altitude, likely in cloud outflows or top of low clouds), which is consistent with the measurements obtained in recent field campaigns such as ACE 1 [Clarke et al., 1999].

[20] As we pointed out earlier in this section, the magnitudes of ionization rate variations during one solar cycle are smaller than $20 \%$ for low latitudes. If a smaller value of ionization rate variation was used, the difference between two curves shown in Figure 4 would be reduced but the altitude-dependent behavior of changes in $\mathrm{CN}$ production would not change.

\section{Implications for Variability of Global Cloudiness}

[21] According to GCR-CN-CCN-cloud hypothesis discussed in section 2 , an increase in ultrafine production rate will increase the $\mathrm{CCN}$ abundance and cloudiness. On the basis of the influence of GCR ionization change on particle formation rate at different altitudes as shown in Figure 4, we can expect that if GCR variations have any impact on cloudiness via GCR-CN-CCN-cloud hypothesis, they should correlate positively with low cloud amount and negatively with high cloud amount. For middle clouds, such a correlation (if any) is likely to be weak.

[22] Analyses of ISCCP-D2 cloud data sets by Marsh and Svensmark [2000a, 2000b] indicate that the low cloud anomalies highly covary with the change of GCR fluxes. During one solar cycle the absolute amount of low cloudiness changes by $\sim 1.5-2 \%$. The fluctuation of middle cloud anomalies is small compared to that of low cloud, and no obvious correlation exists between middle cloudiness and GCR variations. Thus the correlations between GCR variations and low and middle cloud anomalies appear to be consistent with the altitude-dependent influence of GCR variations on $\mathrm{CN}$ production.

[23] For the high cloud anomalies, there is no obvious correlation for the whole solar cycle [Marsh and Svensmark, 2000a, 2000b] while we expect the correlation to be negative. There are several possible explanations for this. First, it takes much longer time for new particles to grow to the size of CCN or ice nuclei (IN) in high altitude than in low altitude due to much lower precursor vapor concentrations. As a result, the initial difference in $\mathrm{CN}$ pro- 


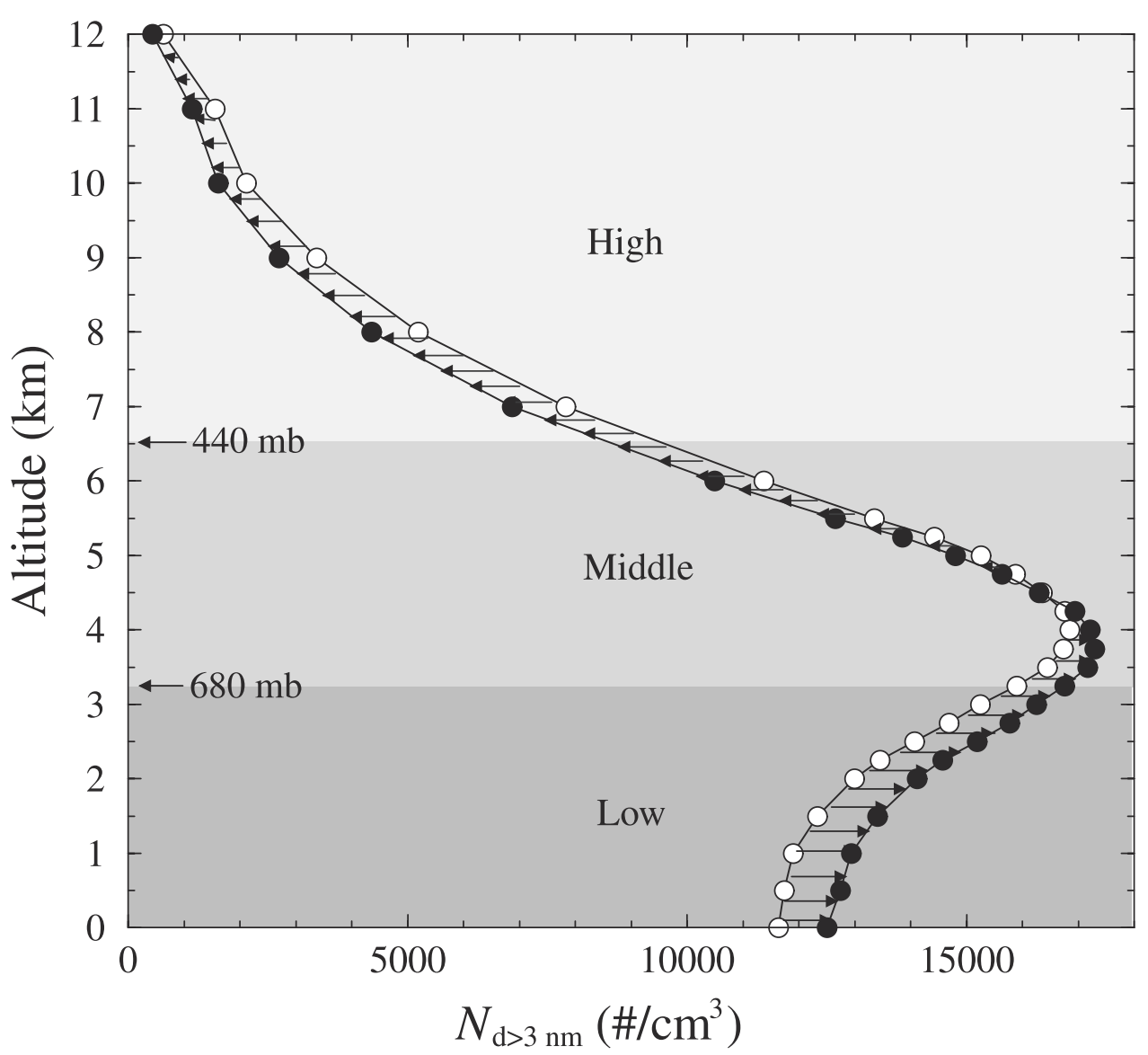

Figure 4. Simulated concentrations of total condensation nuclei larger than $3 \mathrm{~nm}$ after three hours of simulations at different altitudes. The open circles are for the baseline $Q$ values while the closed circles are for $Q$ values $20 \%$ over corresponding baseline values. Thus the arrows indicate the changes in $N_{\mathrm{d}>3 \mathrm{~nm}}$ as ionization rates increase by $20 \%$. The shaded areas are the ranges of $Q$ corresponding to low ( $>680$ mbar), middle (440-680 mbar), and high ( $<440 \mathrm{mbar}$ ) cloud regions as defined in International Satellite Cloud Climatology Project (ISCCP) cloud data.

duction rate may not lead to obvious difference in CCN/IN abundance as a result of coagulation, scavenging, and mixing. Second, the properties of high cloud are determined by ice nuclei abundance that may be insensitive to $\mathrm{CN}$ production rate. The processes controlling IN abundance in high altitude are currently not well known. Third, there may exit a negative correlation, but it does not appear in the ISCCP-D2 data of last solar cycle because of the influence of other processes such as volcano eruptions and El Niño events. The third possibility is further explored below.

[24] We note that there were two major volcano eruptions during the period (El Chichón in April 1982 and Mount Pinatubo in June 1991). Volcano eruptions can inject large amount of $\mathrm{SO}_{2}$ into the stratosphere that leads to the formation of sulfate aerosols. On one hand, the cooling of upper troposphere as a result of volcano eruption may enhance the high cloud formation. On the other hand, the volcano aerosols descending from the stratosphere to the upper troposphere are likely to increase the frequency and lifetime of cirrus clouds [e.g., Jensen and Toon, 1992] and hence high cloudiness. The timescale to disperse the volcanic stratospheric aerosols around the whole globe through meridional circulations is $1-2$ years [e.g., Trepte et al., 1993]. Therefore the effect of volcanic eruptions on global high cloudiness may become obvious 1-2 years after the eruptions. A detailed analysis of Stratospheric Aerosol and Gas Experiment (SAGE) I and II aerosol extinction data for the upper troposphere [Kent et al., 1995, 1998] indicates that a substantial enhancement of aerosols down to $2-3 \mathrm{~km}$ below the tropopause persisted until 1986 for the El Chichón eruption (i.e., 4 years after the eruptions). The high cloudiness in 1987 may have been affected by the El Niño event during that year [Wang et al., 1996].

[25] Figure 5 shows the global average monthly mean anomalies of high IR cloud cover during last solar cycle. To smooth out the seasonal variations, the monthly anomalies are calculated by subtracting the climatic monthly average from each month on an equal area grid before averaging over the globe [Marsh and Svensmark, 2000a, 2000b]. The variations of GCR fluxes as measured from CLIMAX (normalized to May 1965) are also indicated in each panel (dotted-dashed lines). The years of volcano eruptions and El Niño event discussed above are marked, and the shaded areas correspond to the years that 


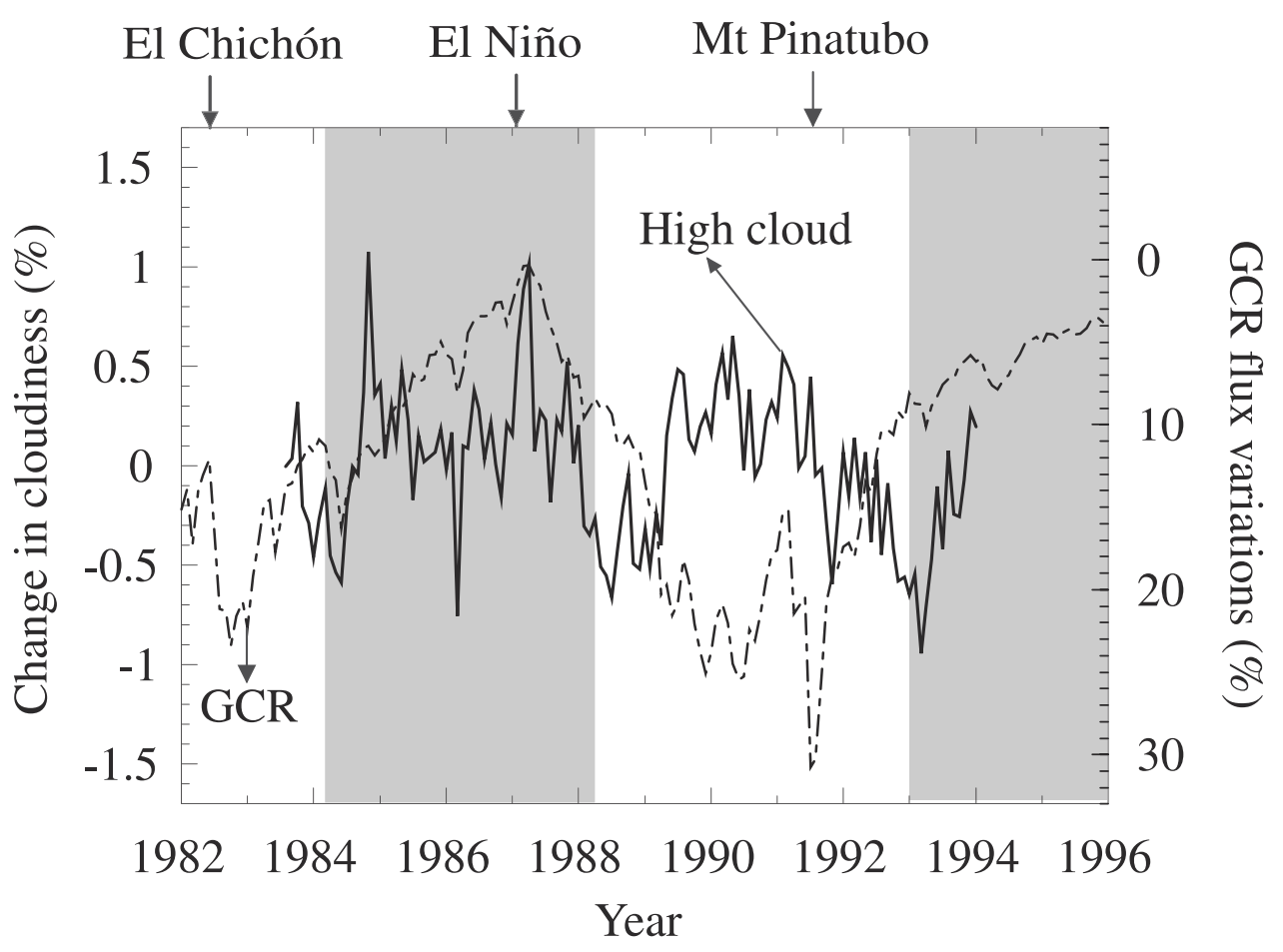

Figure 5. The global average monthly mean anomalies of high IR cloud cover during last solar cycle. The variations of galactic cosmic ray (GCR) fluxes as measured from CLIMAX (normalized to May 1965) are also indicated in each panel (dotted-dashed lines). The shaded areas correspond to the years that global high cloudiness might have been affected by volcano eruptions and El Niño event.

global high cloudiness might have been affected by volcano eruptions and El Niño event. From 1988 to 1993 the impact of volcano eruptions and El Niño on global high clouds is likely negligible, and it is during this period that we find a significant anticorrelation between GCR fluxes and high cloud anomalies. The increase of high cloudiness along with decrease of GCR intensity during 1988-1989 and the decrease of high cloudiness along with increase of GCR intensity during 1991-1992 can be readily explained by the GCR-CN-CCN-cloud hypothesis.

[26] In summary, the predicted different sensitivities of the particle production to cosmic ray changes at different altitudes appear to be consistent with the observed different correlations between cosmic ray variations and low, middle, and high cloud anomalies. However, owing to the limit of cloud cover data available and uncertainties in the volcano and El Niño impacts, our conclusions, especially with regard to the existence of anticorrelation between high cloudiness and cosmic ray variations, are not definitive. More research is obviously needed.

\section{Climate Implications}

[27] Clouds play a key role in the energy budget of Earth's surface and lower atmosphere and are probably the largest contributor to the uncertainty concerning the global climate change [Intergovernmental Panel on Climate Change (IPCC), 1996]. Small modifications of the amount, distribution, or radiative properties of clouds can have significant impacts on the predicted climate [Hart- mann, 1993]. While the first key step of GCR-CN-CCNCloud hypothesis seems to be consistent with the observed spatially dependent correlations of GCR variations and global cloudiness, much more work is needed to clearly establish the GCR-cloud connection. Nevertheless, it is meaningful to discuss the climate implications associated with the possible GCR-induced cloud changes. We assume that the anomalies of high cloud cover correlate negatively while that of low cloud cover correlate positively with GCR variations, and the magnitudes of the fluctuations are similar (1.5-2\% absolute change). As a result of opposite systematic variations of low and high clouds associated with solar activity, the total global cloud cover may show no obvious correlation with GCR variations. However, the radiative effects are unlikely to cancel each other.

[28] The net radiative forcing of clouds depends on their altitude and optical thickness. High optically thin clouds tend to warm while optically thick high and low clouds tend to cool [Hartmann, 1993]. A systematic absolute increase of high cloud amount by $\sim 1.5-2 \%$ and a decrease of low cloud amount by $\sim 1.5-2 \%$ from solar minimum to solar maximum, if confirmed, may represent an important mechanism to amplify the effect of solar variability on Earth's climate. The opposite change in high and low clouds may also change the atmosphere heating profile and the distribution of energy between the atmosphere and the surface and hence may have far-reaching dynamical and climatic consequences. A systematic increase in high cloud may either warm or cool the atmosphere and the Earth's surface below, depending on 
the types of high clouds and the underlying atmospheric properties. For example, it has been shown that the presence of a cirrus stratus (with a base height of $16 \mathrm{~km}$ and thickness of $1.5 \mathrm{~km}$ ) in an otherwise clear tropical atmosphere has a net cooling effect for the atmosphere below $\sim 6 \mathrm{~km}$ but has a net heating effect for the atmosphere above $\sim 6 \mathrm{~km}$ when solar zenith angles are small (less than $\sim 60^{\circ}$ ) [Liou, 1992, p. 305]. A systematic decrease in low cloud is likely to warm the surface by allowing more sunlight to reach the Earth surface, while the same decrease will cool the lower troposphere by reducing the visible absorption in the cloud layer and infrared absorption in the cloud layer and the atmosphere below [Liou, 1992, pp. 393-395].

[29] The long-term trend of global low and high cloud cover as a result of GCR variations may become an important external forcing of Earth climate system. On the basis of these observations, Lockwood et al. [1999] have shown that from 1964 to 1996 the strength of the solar magnetic flux, shielding the Earth from GCR, has increased by $\sim 41 \%$ while GCR has decreased by $\sim 3.7 \%$ [Lockwood et al., 1999]. The ion chamber measurements [Ahluwalia, 1997] also indicate that the sea level GCR intensity has decreased by $\sim 2 \%$ from 1979 to 1994 . The GCR intensity decrease is expected to be larger at higher altitudes in the troposphere. From the data available we estimate that the decrease in GCR fluxes during the past two decades (19791999 ) is $\sim 1 / 3$ to $1 / 2$ of the maximum variations during the last solar cycle. Thus, if the connection between low and high cloudiness exists, the global mean low cloud amount might have been decreasing $(0.25-0.5 \%$ per decade $)$ and high cloud amount increasing $(0.25-0.5 \%$ per decade) during the past two decades.

[30] Such a long-term trend of low and high cloudiness during the past two decades, if real, are likely to have warmed the Earth surface but cooled the lower troposphere. Note that the potential GCR-induced change in cloud albedo and absorption may enhance such an impact (a decrease in cloud droplet concentration due to fewer CCN as a result of reduced GCR fluxes may also imply a reduced cloud albedo and absorption). While the exact amount of net radiative forcing associated with GCR-induced low and high cloud changes remains to be investigated, it is physically plausible that the decrease in GCR fluxes during the past two decades has led to a net warming of $\sim 0.05^{\circ} \mathrm{C}$ per decade at the surface while a net cooling of $\sim 0.05^{\circ} \mathrm{C}$ per decade in the lowest $8 \mathrm{~km}$ of atmosphere. This estimation is largely speculation at this point, but it worth further investigation since the current climate model simulations were not able to reconcile apparent differences between observed surface and troposphere temperature trends (since 1979 when satellite data become available) [e.g., National Research Council (NRC), 2000; IPCC, 2001]. Over the last two decades, the temperature records taken at the Earth's surface show rapid warming (globally $0.15 \pm 0.05^{\circ} \mathrm{C}$ per decade); however, the data produced by satellite and balloon studies indicate little if any warming (globally $0.05 \pm$ $0.10^{\circ} \mathrm{C}$ per decade) of the lowest 5 miles of the atmospheric [e.g., NRC, 2000; IPCC, 2001]. Climate models generally predict that this atmospheric layer should warm faster than the surface due to the greenhouse effect. Gaffen et al, [2000] suggested that the differences may be associated with unidentified (or missing) external forcing. It is of interest and importance to investigate if the GCR-induced cloud changes could be this missing external forcing.

\section{Summary and Discussion}

[31] The dependence of ultrafine production rate on galactic cosmic ray ionization rate at different altitudes has been investigated. Our primary studies indicate that an increase in GCR ionization rate leads to an increase in $\mathrm{CN}$ production in the lower troposphere $(>680 \mathrm{mbar})$, but a decrease in $\mathrm{CN}$ production in the upper troposphere $(<440$ mbar). In the lower troposphere the ionization rate is low and the $\mathrm{H}_{2} \mathrm{SO}_{4}$ concentration is relatively high, the particle formation is limited by ionization rate and an increase in ionization rate leads to an increase in nucleation. In the upper troposphere the ionization rate is very high and the $\mathrm{H}_{2} \mathrm{SO}_{4}$ concentration is relatively low, the particle formation is limited by $\mathrm{H}_{2} \mathrm{SO}_{4}$ concentration and an increase in ionization rate inhibit the nucleation by reducing the lifetime of ion clusters. The average change of $\mathrm{CN}$ production as the ionization rate increases is small in the middle troposphere (440-680 mbar).

[32] Since an increase in ultrafine production rate is likely to increase the $\mathrm{CCN}$ abundance and cloudiness, we can expect that the correlation between GCR changes and global cloud cover (if any) should be positive for low cloud, negative for high cloud, and weak for the middle cloud. In addition to the reported positive correlation between GCR variations and low cloudiness, our analyses of ISCCP D2 IR cloud data further reveal that high cloudiness may be anticorrelated with GCR variations if volcano and El Niño impacts are excluded. During a solar cycle the absolute change of high and low cloud amounts is opposite in sign but similar in magnitude $(\sim 1.5-2 \%)$. The fluctuations of middle cloud anomalies are small compared to that of low clouds, and no obvious correlation exists between middle cloudiness and GCR variations. Therefore the observed different correlations between GCR variations and low, middle, and high cloud anomalies seem to be consistent with the predicted dependence of $\mathrm{CN}$ production on GCR variations at different altitudes. Such a consistency suggests that solar activity might actually affect global cloudiness by modulating GCR fluxes. Meanwhile, considering the limit of cloud cover data available and uncertainties in the volcano and El Niño impacts, we want to emphasize that our conclusions (especially with regard to the existence of anticorrelation between high cloudiness and cosmic ray variations) are not definitive.

[33] The climate implications associated with the possible GCR-induced cloud changes are discussed. Since cloud is critical to Earth radiation budget, opposite systematic variations of low and high clouds associated with solar activity, if confirmed, may represent an important mechanism to amplify the effect of solar variability on Earth's climate. The decrease in GCR intensity during the last two decades might have led to a decrease in global mean low cloud amount and an increase in high cloud amount, which might have warmed the Earth's surface and cooled the low troposphere. We suggest that, the GCR-induced natural variability of global cloudiness, together with the greenhouse gases which warm both the surface and low troposphere, may reconcile 
the apparent differences in global mean temperature trends over the last two decades at Earth's surface (rapidly warming, as recorded by thermometers) and in the lowest $8 \mathrm{~km}$ of atmosphere (little if any warming, as monitored by satellites and balloons).

[34] While this study provides additional evidence for the inferred correlation between variations in global cloud properties and the solar-modulated GCR fluxes, much more work is needed to understand how and how much the GCR variations will affect the $\mathrm{CCN}$ abundance and cloud properties. Laboratory and field measurements, as well as theoretical studies are needed to validate the predicted dependent-behaviors of nucleation on ionization rates at different altitudes, to investigate the effect of GCR variations on CCN abundance, and to clarify the complex microphysics of aerosol/cloud interactions. The current analyses of GCR-cloud correlations are limited by the uncertainties associated with the cloud data and short periods of cloud data available. Improved cloud cover data covering longer time periods will be very useful in studying GCR-cloud connections.

[35] In addition to their possible influence on particle nucleation rate, $\mathrm{CN}$ and $\mathrm{CCN}$ abundance, GCR variations may also affect global electric circuit and electroscavenging [e.g., Tinsley, 2000, 2001] that will change cloud properties. On the other hand, the UV-induced changes in stratospheric ozone and heating rate alter the atmospheric circulation, energy transport and the lower atmosphere temperature [e.g., Haigh, 1996, 1999; Shindell et al., 1999] and thus may also influence the cloud properties. It is important to understand the relative contributions of different mechanisms (hypotheses) to the natural variability of the cloud properties under different atmospheric conditions (or at different altitudes/latitudes).

[36] Acknowledgments. This work was supported by the NSF under grant ATM 0104966.

\section{References}

Ahluwalia, H. S., Galactic cosmic ray intensity variations at a high latitude sea level site 1937-1994, J. Geophys. Res., 102, 24,229-24,236, 1997.

Albrecht, B. A., Aerosols, cloud microphysics, and fractional cloudiness, Science, 245, 1227-1230, 1989.

Birmili, W., and A. Wiedensohler, New particle formation in the continental boundary layer: Meteorological and gas phase parameter influence, Geophys. Res. Lett., 27, 3325-3328, 2000.

Clarke, A. D., V. N. Kapustin, F. L. Eisele, R. J. Weber, and P. H. McMurry, Particle production near marine clouds: Sulfuric acid and predictions from classical binary nucleation, Geophys. Res. Lett., 26, 2425-2428, 1999.

Dickinson, R. E., Solar variability and the lower atmosphere, Bull. Am. Meterol. Soc., 56, 1240-1248, 1975.

Eddy, J. A., The Maunder minimum, Science, 192, 1189-1202, 1976.

Gaffen, D. J., et al., Multidecadal changes in the vertical temperature structure of the tropical troposphere, Science, 287, 1242-1245, 2000.

Haigh, J. D., The impact of solar variability on climate, Science, 272, $981-$ 984, 1996.

Haigh, J. D., A GCM study of climate change in response to the 11-year solar cycle, O. J. R. Meteorol. Soc., 125, 871-892, 1999.

Hartmann, D. L., Radiative effects of clouds on Earth's climate, in AerosolCloud-Climate Interactions, edited by P. V. Hobbs, pp. 33-73, Academic, San Diego, Calif., 1993

Hegg, D. A., Heterogeneous production of cloud condensation nuclei in the marine atmosphere, Geophys. Res. Lett., 17, 2165-2168, 1990.

Hobbs, P. V., Aerosol-cloud interactions, in Aerosol-Cloud-Climate Interactions, edited by P. V. Hobbs, Academic, San Diego, Calif., 1993.

Hudson, J. G., and X. Y. Da, Volatility and size of cloud condensation nuclei, J. Geophys. Res., 101, 4435-4442, 1996.
Intergovernmental Panel on Climate Change (IPCC), Climate Change 1995: The Science of Climate Change, edited by J. T. Houghton et al., Cambridge Univ. Press, New York, 1996.

IPCC, Climate Change 2001: The Scientific Basis, edited by J. T. Houghton et al., Cambridge Univ. Press, New York, 2001.

Jensen, E. J., and O. B. Toon, The potential effects of volcanic aerosols on cirrus cloud microphysics, Geophys. Res. Lett., 19, 1759-1762, 1992.

Jørgensen, T. S., and A. W. Hansen, Comments on "Variation of cosmic ray flux and global cloud coverage-A missing link in solar-climate relationships" by Henrik Svensmark and Eigil Friis-Christensen, J. Atmos. Sol. Terr. Phys., 62, 73-77, 2000.

Kärcher, B., F. Yu, F. P. Schroeder, and R. P. Turco, Ultrafine aerosol particles in aircraft plumes: Analysis of growth mechanisms, Geophys. Res. Lett., 25, 2793-2796, 1998.

Kaufman, Y. J., and D. Tanre, Effect of variations in supersaturation on the formation of cloud condensation nuclei, Nature, 369, 45-48, 1994.

Kelly, P. M., and T. M. L. Wigley, Solar cycle length, greenhouse forcing and global climate change, Nature, 360, 328-330, 1992.

Kent, G. S., P. H. Wang, M. P. McCormick, and K. M. Skeens, Multiyear stratospheric aerosol and gas experiment II measurements of upper tropospheric aerosol characteristics, J. Geophys. Res., 100, 13,875-13,899, 1995.

Kent, G. S., C. R. Trepte, and P. L. Lucker, Long-term stratospheric aerosol and gas experiment I and II measurements of upper tropospheric aerosol extinction, J. Geophys. Res., 103, 28,863-28,874, 1998.

Kernthaler, S. C., R. Toumi, and J. D. Haigh, Some doubts concerning a link between cosmic ray fluxes and global cloudiness, Geophys. Res. Lett., 26, 863-865, 1999.

Kirkby, J., and A. Laaksonen, Solar variability and clouds, Space Sci. Rev, 94, 397-409, 2000.

Kniveton, D. R., and M. Todd, On the Relationship of Cosmic Ray Flux and Precipitation, Geophys. Res. Lett., 28, 1527-1530, 2001

Kristjánsson, J. E., and J. Kristiansen, Is there a cosmic ray signal in recent variations in global cloudiness and cloud radiative forcing?, J. Geophys. Res., 105, 11,851-11,863, 2000.

Kulmala, M., A. Toivonen, J. M. Mäkelä, and A. Laaksonen, Analysis of the growth of nucleation mode particles observed in Boreal forest, Tellus, Ser. B, 50, 449-462, 1998.

Liou, K. N., Radiation and Cloud Processes in the Atmosphere: Theory, Observation, and Modeling, pp. 305 393-395, Oxford Univ. Press, New York, 1992.

Lockwood, M., Changes in GCR flux, solar irradiance and climate over the past 150 years, in Proceeding of Workshop on Ion-Aerosol-Cloud Interactions, CERN, Geneva, Switzerland, 2001

Lockwood, M., R. Stamper, and M. N. Wild, A doubling of the Sun's coronal magnetic field during the past 100 years, Nature, 399, 437439, 1999.

Marsh, N., and H. Svensmark, Cosmic rays, clouds, and climate, Space Sci. Rev., 94, 215-230, 2000a.

Marsh, N., and H. Svensmark, Low cloud properties influenced by cosmic rays, Phys. Rev. Lett., 85, 5004-5007, 2000b.

Millikan, R. A., H. V. Neher, and W. H. Pickering, Further studies on the origin of cosmic rays, Phys. Rev., 66, 295-302, 1944.

Neher, H. V., Cosmic-Rays at high latitudes and altitudes covering four solar maxima, J. Geophys. Res., 76, 1637-1651, 1971

Ney, E. P., Cosmic radiation and the weather, Nature, 183, 451-452, 1959.

Novakov, T., and J. E. Penner, Large contribution of organic aerosols to cloud condensation nuclei concentrations, Nature, 365, 823-826, 1993.

National Research Council, Reconciling Observations of Global Temperature Change, Panel on Reconciling Temperature Obs., Natl. Acad. Press, Washington, D. C., 2000

Palle, E., and C. J. Butler, The influence of cosmic rays on terrestrial clouds and global warming, Astron. Geophys., 41, 18-22, 2000.

Reid, G. C., Solar Varibility and the Earth's climate: Introduction and overview, Space Sci. Rev., 94, 1-11, 2000.

Rossow, W. B., and R. A. Schiffer, Advances in understanding clouds From ISCCP, Bull. Am. Meteorol. Soc., 80, 2261-2287, 1999.

Shaw, G. E., R. L. Benner, W. Cantrell, and A. D. Clarke, On the relation of climate: A sulfate particle feedback loop involving deep convection, Climate Change, 39, 23-33, 1998.

Shindell, D., D. Rind, N. Balachandran, J. Lean, and P. Lonergan, Solar cycle variability, ozone, and climate, Science, 284, 305-308, 1999.

Soon, W. H., E. S. Posmentier, and S. L. Baliunas, Influence of Solar Irradiance variability from terrestrial temperature changes, 1880-1993: An astrophysical application of the Sun-Climate connection, Astrophys. J., 472, 891-902, 1996.

Svensmark, H., and E. Friis-Christensen, Variation of cosmic ray flux and global cloud coverage-A missing link in solar-climate relationships, $J$. Atmos. Sol. Terr. Phys., 59, 1225-1232, 1997. 
Tinsley, B. A., Correlations of atmospheric dynamics with solar wind induced changes in air-Earth current density into cloud tops, J. Geophys. Res., 101, 29,701-29,714, 1996.

Tinsley, B. A., Influence of solar wind on the global electric circuit, and inferred effects on cloud microphysics, temperature, and dynamics in the troposphere, Space Sci. Rev., 94, 231-258, 2000.

Tinsley, B. A., and G. W. Dean, Apparent tropospheric response to MeVGeV particle flux variations: A connection via electrofreezing of supercooled water in high level clouds?, J. Geophys. Res., 96, 22,283-22,296, 1991.

Tinsley, B. A., R. P. Rohrbaugh, and M. Hei, Electroscavenging in clouds with broad droplet size distributions and weak electrification, Atmos. Res., 59-60, 115-135, 2001.

Trepte, C. R., R. E. Veiga, and M. P. McCormick, The poleward dispersal of Mount Pinatubo volcanic aerosol, J. Geophys. Res., 98, 18,563-18,573, 1993.

Twomey, S., The influence of pollution on the shortwave albedo of clouds, J. Atmos. Sci., 34, 1149-1152, 1977.

Twomey, S., Aerosols, clouds and radiation, Atmos. Environ., Part A, 25, 2435-2442, 1991.

Wagner, G., D. M. Livingstone, J. Masarik, R. Muscheler, and J. Beer, Some results relevant to the discussion of a possible link between cosmic rays and the Earth's climate, J. Geophys. Res., 106, 3381-3387, 2001.

Wang, P.-H., P. Minnis, M. P. McCormick, G. S. Kent, and K. M. Skeens, A 6-year climatology of cloud occurrence frequency from Stratospheric Aerosol and Gas Experiment II observations (1985-1990), J. Geophys. Res., 101, 29,407-29,430, 1996.

Weber, R. J., et al., Measurement of new particle formation and ultrafine particle growth rates at a clean continental site, J. Geophys. Res., 102, $4375-4385,1997$.
Weber, R. J., et al., New particle formation in the remote troposphere: A comparison of observations at various sites, Geophys. Res. Lett., 26, 307-310, 1999

Weng, F. Z., and N. C. Grody, Retrieval of cloud liquid water using the special sensor microwave imager (SSM/I), J. Geophys. Res., 99, 25,535$25,551,1994$

Yu, F., Chemiions and nanoparticle formation in diesel engine exhaust, Geophys. Res. Lett., 28, 4191-4194, 2001.

$\mathrm{Yu}, \mathrm{F}$, and R. P. Turco, The role of ions in the formation and evolution of particles in aircraft plumes, Geophys. Res. Lett., 24, 1927-1930, 1997.

Yu, F., and R. P. Turco, Ultrafine aerosol formation via ion-mediated nucleation, Geophys. Res. Lett., 27, 883-886, 2000.

Yu, F., and R. P. Turco, From molecular clusters to nanoparticles: The role of ambient ionization in tropospheric aerosol formation, J. Geophys. Res., 106, 4797-4814, 2001.

Yu, F., R. P. Turco, B. Kärcher, and F. P. Schröder, On the mechanisms controlling the formation and properties of volatile particles in aircraft wakes, Geophys. Res. Lett., 25, 3839-3842, 1998.

Yu, F., R. P. Turco, and B. Kärcher, The possible role of organics in the formation and evolution of ultrafine aircraft particles, J. Geophys. Res., 104, 4079-4087, 1999.

F. Yu, Atmospheric Sciences Research Center, State University of New York at Albany, 251 Fuller Road, Albany, NY 12203, USA. (yfq@asrc. cestm.albany.edu) 